\title{
Exact and limiting distributions in diagonal Pólya processes
}

\author{
Srinivasan Balaji • Hosam M. Mahmoud
}

Published online: 24 November 2006

(C) The Institute of Statistical Mathematics, Tokyo 2006

\section{Erratum to: AISM 58: 171-185 DOI 10.1007/s10463-005-0012-x}

The original version of the history unfortunately contained a mistake. The correct approval history is given here.

Received: 6 May 2004 / Revised: 12 May 2004

The online version of the original article can be found at http://dx.doi.org/10.1007/s10463-005-0012-x.

S. Balaji · H. M. Mahmoud ( $\bowtie)$

Department of Statistics, The George Washington University, Washington, DC 20052, USA

e-mail:balaji@gwu.edu

H. M. Mahmoud e-mail: hosam@gwu.edu 